\title{
Estudo do potencial de adsorção de íons de ferro de água contaminada com drenagem ácida de mina utilizando geopolímero à base de cinza da casca de arroz e resíduo cerâmico
}

\author{
Removal of iron ions from water contaminated with acid mine drainage \\ by geopolymer derived from rice husk ash and ceramic residue
}

\author{
Sabrina Wesler ${ }^{1} \oplus$, Isabel Conceição de Brida' ${ }^{\oplus}$, Reginaldo Geremias' ${ }^{1}$, \\ Carlyle Torres Bezerra de Menezes $^{2} \stackrel{\oplus}{ }$, Tatiana Pineda-Vasquez ${ }^{1 *}$ (1)
}

\begin{abstract}
RESUMO
A drenagem ácida de mina da mineração de carvão é um dos mais graves problemasambientaisqueexistematualmenteeécaracterizada, principalmente, por apresentar elevada acidez, baixo pH e expressiva concentração de metais tóxicos, como ferro, Mn e muitos outros, afetando diretamente mananciais e rios. Em busca de uma alternativa que pudesse melhorar, de forma eficiente e econômica, os níveis de acidez e ferro da água impactada pela drenagem ácida de mina, foi desenvolvido um adsorvente geopolimérico à base de materiais residuais da indústria cerâmica e do beneficiamento de arroz (cinzas da casca de arroz). O objetivo desta pesquisa foi avaliar a eficiência do geopolímero na remoção de íons ferro em água contaminada com drenagem ácida de mina. Foram avaliados aspectos de dosagem do adsorvente, efeito da temperatura, concentrações iniciais de ferro, cinética e parâmetros termodinâmicos do processo de adsorção. O percentual de ferro removido foi de 92,76\%, à temperatura de $25{ }^{\circ} \mathrm{C}$, em um período de 20 min, com uma concentração de adsorvente de $4 \mathrm{~g} \mathrm{~L}^{-1}$. A capacidade máxima de adsorção de ferro pelo geopolímero foi de 7,18 mg.g! O principal mecanismo de adsorção ocorreu em razão da quimissorção, que segue o modelo cinético de pseudossegunda ordem. O geopolímero se mostrou como uma alternativa eficiente ao tratamento de água contaminada com drenagem ácida de mina.
\end{abstract}

Palavras-chave: drenagem ácida de mina; adsorção; resíduos; geopolímero.

\begin{abstract}
Acid mine drainage is a worldwide problem and is characterized by high acidity, low $\mathrm{pH}$ and expressive concentration of heavy metals, such as iron, $\mathrm{Mn}$ and many others, directly affecting water sources and rivers. In search of an alternative that could efficiently and economically improve the levels of acidity and water iron impacted by acid mine drainage, a geopolymeric adsorbent based on residual materials was developed: from the ceramic industry and rice processing (rice husk ash). In this work, it was evaluated the efficiency of the geopolymer in removing iron ions in water contaminated with acid mine drainage. Aspects of adsorbent dosage, temperature effect, initial iron concentrations, kinetics and thermodynamic parameters of the adsorption process were evaluated. The percentage of iron removed was $92.76 \%$, at a temperature of $25{ }^{\circ} \mathrm{C}$, for 20 min, with an adsorbent concentration of $4 \mathrm{~g} \mathrm{~L}^{-1}$, with the maximum capacity for adsorption of iron by the geopolymer being $7.18 \mathrm{mg} . \mathrm{g}^{-1}$. The main mechanism of adsorption occurred due to chemisorption, which follows the kinetic model of pseudo-second order. Geopolymer appears potentially useful an efficient alternative in the treatment of water contaminated with acid mine drainage.
\end{abstract}

Keywords: acid mine drainage; adsorption of iron; waste; geopolymer

\section{INTRODUÇÃO}

O carvão mineral é um dos principais combustíveis usados para a geração de eletricidade em todo o mundo. Atualmente, os maiores produtores de carvão mineral são a China, os Estados Unidos, a Austrália, a Rússia e a Indonésia
(LOSEKANN \& TAVARES, 2019). No Brasil, as principais reservas se encontram no Rio Grande do Sul, Santa Catarina, Paraná, Minas Gerais, São Paulo e Bahia. Na atividade carbonífera são gerados efluentes ácidos e rejeitos piritosos, os quais são capazes de provocar diversos impactos ambientais negativos.

Universidade Federal de Santa Catarina - Florianópolis (SC), Brasil.

¿Universidade do Extremo Sul Catarinense - Florianópolis (SC), Brasil.

*Autor correspondente: latatiss@gmail.com

Conflitos de interesse: os autores declaram não haver conflitos de interesse.

Financiamento: nenhum.

Recebido: 06/O4/2O2O - Aceito: 19/12/2O2O - Reg. ABES: 20200123 
A drenagem ácida de minas (DAM) é o problema ambiental que mais preocupa a região carbonífera catarinense, especialmente em razão da intensidade com que contamina solos e águas. Segundo Simate e Ndlovu (2014), a pirita $\left(\mathrm{FeS}_{2}\right)$ está entre os principais elementos capazes de gerar drenagem ácida. A DAM é formada a partir de uma sequência de mecanismos de oxidação de sulfetos, na presença do oxigênio, catalisada pela atividade das bactérias acidófilas como Thiobacillus thiooxidans e ferrooxidans, resultando na liberação de íons hidrogênio, íons sulfato e cátions metálicos solúveis. Esse processo de oxidação ocorre inicialmente em uma taxa lenta, e o ambiente é capaz de tamponar o ácido gerado (SIMATE \& NDLOVU, 2014).

A água impactada pela drenagem ácida de mina (AIDAM) apresenta pH ácido e, dependendo das condições geológicas específicas, contém concentrações elevadas de íons metálicos dissolvidos (ex: ferro - Fe, manganês - Mn, zinco - Zn, As, cádmio - $\mathrm{Cd}$, cobre - $\mathrm{Cu}$, níquel - $\mathrm{Ni}$, chumbo - $\mathrm{Pb}$, alumínio - $\mathrm{Al}$, cromo - $\mathrm{Cr}$, e magnésio - $\mathrm{Mg}$ ), que podem apresentar riscos à saúde e ao meio ambiente (FUNGARO \& IZIDORO, 2006). Os métodos mais comuns para o tratamento da DAM e de águas por ela impactadas envolvem a neutralização da acidez com agentes alcalinos (PARK et al., 2019), precipitação dos íons metálicos na solução aquosa e retenção das espécies dissolvidas (JOHNSON \& HALLBERG, 2005; UBALDO \& SOUZA, 2008). Esses métodos podem ser ativos ou passivos e envolver processos químicos e/ou biológicos (GENTY et al., 2016), como flotação (SILVEIRA, SILVA \& RUBIO, 2009), osmose reversa (VITAL et al., 2018), biorremediação (YOUNGER et al., 2003) e adsorção (RASAKI et al., 2019). Segundo Javadian et al. (2015), o método de adsorção, entre todos os processos acima mencionados, é o mais favorável, visto que é economicamente vantajoso, altamente eficiente e aplicável. Adsorventes comuns, como o carvão ativado, são considerados bons adsorventes, apresentando grande capacidade de adsorção (KHARRAZI et al., 2020). No entanto, seu alto custo de produção dificulta uma aplicação mais ampla. Assim, é necessário o desenvolvimento de adsorventes alternativos e de baixo custo, como é o caso dos geopolímeros (NOVAIS et al., 2016).

Os geopolímeros podem ser sintetizados por meio de minerais naturais/ sintéticos de aluminossilicato ou de subprodutos/resíduos de aluminossilicato industrial (como metacaulim, cinzas volantes, escórias, lama vermelha, areia, casca de arroz, argila ou uma combinação destes) misturados com uma solução ativadora (potássio/hidróxido de sódio, ácido fosfórico, silicato de potássio/sódio etc.) (ASIM et al., 2019; BAI \& COLOMBO, 2018). Esses materiais são considerados econômicos e inovadores no contexto de remoção de poluentes da água e do ar. O desempenho catalítico do geopolímero está intimamente ligado à sua composição, microestrutura e método de preparação (RASAKI et al., 2019).

Entre os materiais sorventes alternativos, a cinza da casca de arroz (CCA) assume uma elevada importância, uma vez que permite o desenvolvimento de materiais de baixo custo a partir de resíduos agrícolas ou industriais. Dessa forma, a CCA pode ser utilizada numa variedade de aplicações, como: cobertura de telhas, inseticidas e biofertilizantes, pinturas especializadas, retardadores de incêndio, impermeabilização de produtos químicos, entre outras (SANDHU \& SIDDIQUE, 2017). Além disso, no processo cerâmico, aproximadamente $30 \%$ dos materiais se tornam resíduos, que são depositados diretamente em aterros. Esses resíduos são compostos, basicamente, de alumina e sílica $\left(\mathrm{SiO}_{2}\right)$, substâncias necessárias na constituição de materiais geopoliméricos (SUN et al., 2013; ROSSI et al., 2017).
O estudo realizado por Jeremias, Pineda e Lobo-Recio (2018) avaliou a eficiência de remoção dos íons $\mathrm{Fe}$, $\mathrm{Al}$ e $\mathrm{Mn}$ e da acidez para a remediação de águas fluviais contaminadas pela DAM a partir da cinza da casca do arroz obtida por diferentes temperaturas de calcinação, pretendendo obter, após o tratamento, uma água apta para o reuso secundário não potável. Foi observada a remoção expressiva de íons $\mathrm{Fe}$ (> 98\%), mas houve um aumento da concentração de íons Mn na solução e uma baixa eficiência de remoção de íons $\mathrm{Al}$ ( 35\%), demonstrando que a CCA tem potencial para ser usada como adsorvente nos processos envolvendo a DAM.

Na Tabela 1 são apresentados diversos estudos envolvendo os processos de adsorção de metais pesados de diferentes sistemas e de DAM, utilizando diferentes adsorventes, incluindo-se geopolímeros. São poucos os estudos que utilizam geopolímeros baseados em materiais residuais para o tratamento de água contaminada com a DAM embora eles tenham demonstrado apresentar uma eficiência elevada para remoção de diferentes metais em soluções sintéticas.

Diante do exposto, a presente pesquisa teve por objetivo avaliar a adsorção de íons Fe em água contaminada com DAM, utilizando geopolímero à base de CCA e resíduo cerâmico (RC), assim como estudar o equilíbrio, a cinética, as isotermas de adsorção e os parâmetros termodinâmicos que envolvem o processo de adsorção.

\section{METODOLOGIA}

\section{Cinza da casca de arroz}

A CCA foi fornecida pela Indústria e Comércio de Arroz Fumacense Ltda., localizada no município de Morro da Fumaça, Santa Catarina, Brasil. A cinza é um subproduto gerado pela própria usina no processo de queima da casca de arroz para aproveitar sua energia na etapa de beneficiamento do arroz.

\section{Resíduo cerâmico}

O RC foi disponibilizado pela empresa Angelgres, instalada em Criciúma, Santa Catarina, Brasil. Esse resíduo é gerado após o processo de conformação das peças e antes de passar pelos fornos de secagem, a partir de objetos defeituosos, cujo material não pode ser mais reincorporado ao processo produtivo. $\mathrm{O}$ material foi seco em estufa por $24 \mathrm{~h}$ à $104^{\circ} \mathrm{C}$ para retirar a umidade e ser empregado na formulação do geopolímero.

\section{Água impactada com a drenagem ácida de mina}

As amostras de água impactadas com a DAM foram coletadas em um ponto do rio Sangão, no município de Criciúma, Santa Catarina. O local apresenta coordenadas geográficas de latitude $28^{\circ} 44^{\prime} 13.6^{\prime \prime}$ e e longitude $49^{\circ} 24^{\prime} 25.5^{\prime \prime} \mathrm{W}$.

A coleta foi realizada em um ponto próximo a uma área de rejeitos piritosos, confinados em uma célula de contenção de rejeitos, conforme a metodologia relatada por Núñes-Gómes et al. (2019). As amostras foram armazenadas em recipientes de polietileno, com capacidade de $5 \mathrm{~L}$ e, posteriormente, mantidas sob refrigeração, seguindo a norma NBR 9898. Uma parcela da amostragem foi enviada para análise no laboratório de águas e efluentes industriais do Instituto de Pesquisas Ambientais Tecnológicas (IPAT). Sua avaliação foi realizada por meio de metodologia padronizada por Standard Methods for the Examination of Water and Wastewater (SMEWW). 


\section{Produção do adsorvente geopolimérico}

Para a produção do adsorvente geopolimérico, foram utilizados CCA e RC. Esses resíduos foram cominuídos a seco, por meio de um moinho de bolas de alumina, e peneirados antes de serem misturados, a fim de ter uma superfície mais homogênea e área superficial maior. A análise de distribuição do tamanho da partícula indicou o tamanho médio $\mathrm{D}_{50}$ igual a $0,227 \mu \mathrm{m}$ para CCA e o tamanho médio $\mathrm{D}_{50}$ correspondente a $0,591 \mu \mathrm{m}$ para RC.

Para a reação de geopolimerização, foi utilizado o ativador alcalino hidróxido de sódio $(\mathrm{NaOH})$ com $99 \%$ de pureza da marca Neon. A solução de $\mathrm{NaOH}$ $9 \mathrm{M}$ foi preparada utilizando lentilhas dissolvidas em água destilada, à temperatura ambiente de $25^{\circ} \mathrm{C}$.
As formulações das pastas geopoliméricas foram preparadas pela mistura de RC + CCA com uma razão mássica de 1:1. Para a geopolimerização, utilizou-se a relação sólido-solução alcalina em massa de 1,2 (g.g $\left.{ }^{-1}\right)$. As pastas foram moldadas em cilindros de PVC, com $20 \mathrm{~mm}$ de diâmetro e $40 \mathrm{~mm}$ de altura, curadas por 15 dias em estufa, à temperatura de $50^{\circ} \mathrm{C}$. Uma vez conformado e curado, o geopolímero foi lavado para retirar o excesso de $\mathrm{NaOH}$, seco em estufa por $24 \mathrm{~h}$, à $50^{\circ} \mathrm{C}$, e submetido à moagem. O procedimento foi realizado pelo Laboratório de Análises e Ensaios de Carvão (LAEC), da Associação Beneficente da Indústria Carbonífera de Santa Catarina (SATC), para obtenção de um pó homogêneo com elevada área específica e granulometria $\mathrm{D}_{50}$ igual a $0,50 \mathrm{~mm}$.

Tabela 1 - Estudos de adsorção de metais pesados usando diferentes adsorventes.

\begin{tabular}{|c|c|c|c|c|c|c|}
\hline Referência & Adsorvente & Amostra & $\begin{array}{l}\text { Espécie } \\
\text { removida }\end{array}$ & $\mathrm{pH}$ & Capacidade de adsorção $\left(\mathrm{q}_{\mathrm{e}}\right)$ & $\begin{array}{l}\text { Eficiência de } \\
\text { remoção (\%) }\end{array}$ \\
\hline Al-Harahsheh, M. S et al. (2015) & $\begin{array}{l}\text { Geopolímero à base de } \\
\text { cinzas volantes }\end{array}$ & Solução aquosa & $\mathrm{Cu}^{2+}$ & 6,0 & $152,3 \mathrm{mg} \cdot \mathrm{g}^{-1}$ & \\
\hline Liu, Y. et al. (2016) & $\begin{array}{l}\text { Geopolímero à base de } \\
\text { cinzas volantes, cinzas } \\
\text { volantes e bloco de } \\
\text { faujasita }\end{array}$ & Solução aquosa & $\mathrm{Pb}^{2+}$ & 3,0 & $\begin{array}{c}\text { Geopolímero à base de cinzas } \\
\text { volantes }=118,6 \mathrm{mg} \cdot \mathrm{g}^{-1} \\
\text { Cinzas volantes }=49,8 \mathrm{mg} \cdot \mathrm{g}^{-1} \\
\text { Bloco de faujasita }=143,3 \mathrm{mg} \cdot \mathrm{g}^{-1}\end{array}$ & \\
\hline Luukkonen et al. (2016) & $\begin{array}{l}\text { Geopolímero de escória } \\
\text { de alto forno }\end{array}$ & DAM & $\begin{array}{l}\mathrm{Ni}^{2+} \\
\mathrm{As}^{3+} \\
\mathrm{Sb}^{3+}\end{array}$ & $7,0-8,0$ & $\begin{array}{l}\mathrm{Ni}=4,42 \mathrm{mg} \cdot \mathrm{g}^{-1} \\
\mathrm{As}=0,52 \mathrm{mg} \cdot \mathrm{g}^{-1} \\
\mathrm{Sb}=0,34 \mathrm{mg} \cdot \mathrm{g}^{-1}\end{array}$ & $90-100 \%$ \\
\hline Kara, Yilmazer e Akar (2017) & $\begin{array}{l}\text { Geopolímero à base de } \\
\text { metacaulim }\end{array}$ & Solução aquosa & $\begin{array}{l}\mathrm{Zn}^{2+} \\
\mathrm{Ni}^{2+}\end{array}$ & $\begin{array}{l}\mathrm{Zn}=6,39 \\
\mathrm{Ni}=7,25\end{array}$ & $\begin{array}{l}\mathrm{Zn}=1,1410^{-3} \mathrm{~mol} \cdot \mathrm{g}^{-1} \\
\mathrm{Ni}=7,2610^{-4} \mathrm{~mol} \cdot \mathrm{g}^{-1}\end{array}$ & \\
\hline $\begin{array}{l}\text { Jeremias, T.; Pineda-Vásques, } \\
\text { T.; Lobo-Recio, M. (2018) }\end{array}$ & Cinza da casca de arroz & $\begin{array}{l}\text { Água fluvial } \\
\text { com DAM }\end{array}$ & $\begin{array}{l}\text { lons Fe, Al } \\
\text { e Mn }\end{array}$ & $2,88-3,56$ & $\begin{array}{l}\text { Aumento } 45 \% \text { da concentração } \\
\text { de Mn na solução }\end{array}$ & $\begin{array}{l}\mathrm{Fe}(>98 \%) \\
\mathrm{Al}(\sim 35 \%)\end{array}$ \\
\hline $\begin{array}{l}\text { Fontana, I.; Michael Peterson, } \\
\text { M.; e Cechinel, M. (2018) }\end{array}$ & Resíduo da cerveja & $\begin{array}{l}\text { Solução aquosa } \\
\text { com DAM }\end{array}$ & lons Fe e Mn & 5,3 & $\begin{array}{c}\mathrm{Fe}=4 \pm 1 \mathrm{mg} \cdot \mathrm{g}^{-1} \\
\mathrm{Mn}=0,96 \pm 0,06 \mathrm{mg} \cdot \mathrm{g}^{-1}\end{array}$ & $\begin{array}{l}\mathrm{Fe}=87 \% \\
\mathrm{Mn}=71 \%\end{array}$ \\
\hline Núñez-Gómez et al. (2019) & $\begin{array}{c}\text { Casca de camarão in } \\
\text { natura }\end{array}$ & DAM & ĺons Fe e Mn & $3,49-6,77$ & $\begin{array}{l}\mathrm{Fe}=17,43 \mathrm{mg} \cdot \mathrm{g}^{-1} \\
\mathrm{Mn}=3,87 \mathrm{mg} \cdot \mathrm{g}^{-1}\end{array}$ & $\begin{array}{l}\text { Fe (até 90\%) } \\
\text { Mn (até 88\%) }\end{array}$ \\
\hline Maleki et al. (2019) & Argila bentonita & $\begin{array}{l}\text { Águas residuais } \\
\text { industriais }\end{array}$ & $\begin{array}{c}\text { Metais } \\
\text { pesados } \\
\text { como } \mathrm{Cu}, \mathrm{Pb} \text {, } \\
\mathrm{Ni}, \mathrm{Cd} \text { e Hg }\end{array}$ & 7,0 & & $\begin{array}{l}\mathrm{Cu}(99 \%) \\
\mathrm{Pb}(99 \%) \\
\mathrm{Ni}(92 \%) \\
\mathrm{Cd}(96 \%) \\
\mathrm{Hg}(92 \%)\end{array}$ \\
\hline Yan et al. (2019) & $\begin{array}{l}\text { Microesferas ocas de } \\
\text { ganga }\end{array}$ & Solução aquosa & $\begin{array}{l}\mathrm{Cu}^{2+} \\
\mathrm{Cd}^{2+} \\
\mathrm{Zn}^{2+} \\
\mathrm{Pb}^{2+}\end{array}$ & 2,0-30 & $\begin{array}{l}\mathrm{Cu}^{2+}=13,38 \mathrm{mg} \cdot \mathrm{g}^{-1} \\
\mathrm{Cd}^{2+}=10,83 \mathrm{mg} \cdot \mathrm{g}^{-1} \\
\mathrm{Zn}^{2+}=6,48 \mathrm{mg} \cdot \mathrm{g}^{-1} \\
\mathrm{~Pb}^{2+}=61,4 \mathrm{mg} \cdot \mathrm{g}^{-1}\end{array}$ & \\
\hline Ryu et al. (2020) & $\begin{array}{l}\text { Sílica mesoporosa } \\
\text { modificada com Mn e } \\
\text { enxerto de amina }\end{array}$ & DAM sintética & $\mathrm{Cu}^{2+}$ & $2,0-2,2-5,0-5,2$ & $\begin{array}{c}\text { 24,53 mg.g para DAM tratada } \\
\text { com KOH e 18,11 mg.g para DAM } \\
\text { tratada com NaOH }\end{array}$ & \\
\hline Larazatou C. et al. (2O2O) & $\begin{array}{l}\text { Fibras de palygorskita e } \\
\text { nanotubos de haloisita }\end{array}$ & Solução aquosa & $\mathrm{Fe}^{2+}$ & $\begin{array}{l}\text { Ca-Pal }(4,0-6,0) \\
\text { Ca-Hall }(\mathrm{pH}>8)\end{array}$ & & $\begin{array}{l}\text { Ca-Pal }=99,8 \% \\
\text { Ca-Hall }=91,2 \%\end{array}$ \\
\hline Ngueagni et al. (2020) & Núcleo do chifre do boi & $\begin{array}{l}\text { Água fluvial } \\
\text { com metais }\end{array}$ & $\mathrm{Cu}^{2+}$ & $4,12-4,64$ & $99,98 \mathrm{mg} \cdot \mathrm{g}^{-1}$ & \\
\hline He et al. (2020) & $\begin{array}{l}\text { Zeólita tipo A derivada } \\
\text { de cinzas volantes de } \\
\text { carvão }\end{array}$ & $\begin{array}{l}\text { Águas residuais } \\
\text { industriais }\end{array}$ & $\mathrm{Ni}^{2+}$ & 7,0 & 47,0 mg.g $g^{-1}$ & $94 \%$ \\
\hline Sahoo et al. (2O2O) & Bactérias e algas & DAM & $\begin{array}{c}\text { İons Fe, Al, Mn, } \\
\text { Cu, Ti, Si e S }\end{array}$ & $4,3-7,0$ & & $95-99 \%$ \\
\hline Liu et al. (2021) & $\mathrm{MnFe}_{2} \mathrm{O}_{4}$-Biocarvão & $\begin{array}{c}\text { Águas residuais } \\
\text { industriais }\end{array}$ & $\mathrm{TI}(\mathrm{l})$ & 6,0 & $170,55 \mathrm{mg} \cdot \mathrm{g}^{-1}$ & $49,61 \%$ \\
\hline
\end{tabular}

DAM: drenagem ácida de mina.

Fonte: elaborada pelos autores. 


\section{Caracterização do adsorvente geopolimérico}

$\mathrm{O}$ adsorvente geopolimérico foi caracterizado física e quimicamente. A microestrutura do geopolímero foi verificada através da Microscopia Eletrônica de Varredura (MEV), em um microscópio de bancada - Hitachi, TM3030. A porosidade foi avaliada pela análise de imagem, utilizando-se software Image J. A área superficial foi obtida pelo Método de BET (Braunauer, Emmet e Teller), realizado no equipamento Quantachrome Instruments Autosorb-1. Por fim, a composição química foi analisada por meio da fluorescência de raios $\mathrm{X}$, em um espectrômetro Panalytical Axios.

\section{Avaliação da adsorção de ferro da água impactada pela drenagem ácida de mina}

Os ensaios de adsorção de Fe presente nas amostras de água impactada pela DAM foram realizados no Laboratório de Bioquímica e Microbiologia Aplicados a Processos Biotecnológicos (PROBIOTEC), da Universidade Federal de Santa Catarina (UFSC). Os testes foram conduzidos em batelada, usando um agitador com controle de temperatura da marca Nova Ética, sob agitação constante de $100 \mathrm{rpm}$ e em temperatura controlada. As análises foram realizadas em duplicata. Após o período de adsorção, as amostras foram filtradas a vácuo, com membranas de acetato de celulose (tamanho do poro de $0,45 \mu \mathrm{m}$, da marca Analítica) e com o auxílio do suporte para filtros em policarbonato (diâmetro de $47 \mathrm{~mm}$, da marca Sartorius Stedim Biotech). As concentrações dos íons Fe foram determinadas antes e após os ensaios, através de espectroscopia UV-VIS, por meio da análise fotocolorimétrica, utilizando o espectrofotômetro da marca $\mathrm{HACH}^{\circledast} \mathrm{DR} / 2010$. O reagente utilizado na quantificação de $\mathrm{Fe}$ faz parte do kit para espectroscopia no visível, também da marca $\mathrm{HACH}^{\circledast}$. Os critérios de análise foram baseados na metodologia adaptada de Standard methods for the examination of water and wasterwater, Método 8008 FerroVer Method, com faixa de detecção de Fe total de 0-3 mg. $\mathrm{L}^{-1}$. O pH das amostras foi avaliado antes e após os ensaios de adsorção, utilizando-se pHmetro de bancada do modelo RS 232, marca MS Tecnopon.

\section{Avaliação do efeito da dosagem do adsorvente}

Foram realizados três ensaios, com doses distintas de geopolímero de 4, 12 e $20 \mathrm{~g} \mathrm{~L}^{-1}$, em duplicata, à $25^{\circ} \mathrm{C}$. Após pesadas, cada uma das dosagens do adsorvente foi colocada em contato com $50 \mathrm{~mL}$ de amostra da água impactada pela DAM, em erlenmeyers de $100 \mathrm{~mL}$, sob agitação de $100 \mathrm{rpm}$, à $25^{\circ} \mathrm{C}$, durante um período de 120 min para atingir o equilíbrio, o qual foi determinado em testes preliminares. Após o adsorvente entrar em contato com a AIDAM, foi realizada a medição do $\mathrm{pH}$ de cada amostra. Finalizado o período de adsorção do metal, realizou-se a filtragem e fez-se a análise da concentração de Fe da solução em equilíbrio. Para obter valores da capacidade de adsorção (q), realizou-se um balanço de massa com base na Equação (1).

$q=\frac{\left(C_{o}-C_{e}\right) \cdot V}{m}$

Em que:

$\mathrm{q}=$ capacidade de adsorção $\left(\mathrm{mg} \cdot \mathrm{g}^{-1}\right)$;

$\mathrm{C}_{\mathrm{o}}=$ concentração inicial do adsorvato $\left(\mathrm{mg} \cdot \mathrm{L}^{-1}\right)$;

$\mathrm{C}_{\mathrm{e}}=$ concentração do adsorvato no equilíbrio $\left(\mathrm{mg} \cdot \mathrm{L}^{-1}\right)$;

$\mathrm{V}=$ volume da solução $(\mathrm{L})$;

$\mathrm{m}=$ massa do adsorvente $(\mathrm{g})$.

\section{Cinética de adsorção}

Com o objetivo de avaliar o comportamento cinético da adsorção, realizaram-se quatro ensaios em batelada para diferentes tempos de contato $(10,20,30$ e $60 \mathrm{~min})$, e com duplicata, à temperatura ambiente de $25{ }^{\circ} \mathrm{C}$. Em seguida, erlenmeyers de $100 \mathrm{~mL}$ foram preparados com $50 \mathrm{~mL}$ de AIDAM, com concentração inicial $\left(\mathrm{C}_{\mathrm{o}}\right)$ de Fe estimada em 31,06 mg.L $\mathrm{L}^{-1}$ e 4 g.L. $\mathrm{L}^{-1}$ de adsorvente, sob agitação de $100 \mathrm{rpm}$. Ao fim de cada período de adsorção, as amostras foram filtradas, e determinou-se a concentração residual de $\mathrm{Fe}$ da solução sobrenadante.

Foram usados os modelos de pseudoprimeira ordem e pseudossegunda ordem para representar o processo cinético de adsorção de Fe pelo geopolímero em água impactada pela DAM, os quais são amplamente usados em sistemas de adsorção de monocomponente e multicomponentes (KARA, YILMAZER \& AKAR, 2017).

\section{Modelo de pseudoprimeira ordem}

O modelo cinético de pseudoprimeira ordem foi representado pela expressão linear na Equação 2.

$\ln \left(\mathrm{q}_{\mathrm{e}}-\mathrm{q}_{\mathrm{t}}\right)=\ln \mathrm{q}_{\mathrm{e}}-\mathrm{k} 1 \cdot \mathrm{t}$

Em que: $\mathrm{q}_{\mathrm{e}}$ e $\mathrm{q}_{\mathrm{t}}$ são a capacidade de adsorção no equilíbrio e no tempo $\mathrm{t}\left(\mathrm{mg} \cdot \mathrm{g}^{-1}\right)$, respectivamente; $\mathrm{k}_{1}\left(\mathrm{~min}^{-1}\right)$ é a constante de velocidade de pseudoprimeira ordem.

\section{Modelo de pseudossegunda ordem}

A forma linear do modelo de pseudossegunda ordem, o qual indica que a adsorção acontece principalmente por quimissorção (HO \& MCKAY, 1999), é expressa pela Equação 3.

$\frac{t}{q_{t}}=\frac{1}{\mathrm{~K}_{2} \mathrm{q}_{\mathrm{e}}^{2}}+\frac{1}{\mathrm{q}_{\mathrm{e}}} \mathrm{t}$

Em que: $\mathrm{q}_{\mathrm{e}} \mathrm{e} \mathrm{q}_{\mathrm{t}}$ são a capacidade de adsorção no equilíbrio e no tempo $\mathrm{t}\left(\mathrm{mg} \cdot \mathrm{g}^{-1}\right) ; \mathrm{K}_{2}$ é a constante de velocidade $\left(\mathrm{g} \cdot \mathrm{mg}^{-1} \mathrm{~min}^{-1}\right)$. Os valores de $\mathrm{K}_{2}$ e $\mathrm{q}_{\mathrm{e}}$ podem ser determinados através da plotagem do gráfico $\mathrm{t} / \mathrm{q}_{\mathrm{t}}$ versus $\mathrm{t}$.

\section{Avaliação do efeito da temperatura e isotermas de adsorção}

Para determinar o efeito da temperatura no processo de adsorção, foram elaboradas três isotermas (298K, 303K e 308K) em duplicata, variando as concentrações iniciais da água impactada pela DAM e a concentração inicial de Fe nas amostras. Para obter diferentes concentrações, a amostra de AIDAM original foi diluída com água destilada. Prepararam-se quatro soluções com as proporções de 25, 50, 75 e 100\%. Cada ensaio foi conduzido por $60 \mathrm{~min}$, sob agitação de $100 \mathrm{rpm}$. Após esse período, as amostras foram filtradas, e determinou-se a concentração de Fe no equilíbrio.

Foram utilizados os modelos de Langmuir e Freundlich para representar as isotermas, expressos pelas Equações 4, 5 e 6 seguintes:

$\frac{1}{q_{e}}=\frac{1}{q_{\max }}+\frac{1}{q_{\max } K_{L}} \cdot \frac{1}{C_{e}}$

Em que: $\mathrm{q}_{\mathrm{e}} \mathrm{e}$ a capacidade de adsorção no equilíbrio $\left(\mathrm{mg} \cdot \mathrm{g}^{-1}\right) ; \mathrm{q}_{\max }$ é a capacidade máxima de adsorção em monocamada ( $\left.\mathrm{mg}^{-\mathrm{g}^{-1}}\right)$; $\mathrm{K}_{\mathrm{L}}$ é a constante da isoterma de Langmuir ( $\left.\mathrm{Lmg}^{-1}\right)$; $\mathrm{C}_{\mathrm{e}}$ é a concentração de adsorvato no equilíbrio (mg. $\left.\mathrm{L}^{-1}\right)$. 
As características essenciais da isoterma de Langmuir podem ser analisadas por meio de um parâmetro de equilíbrio, $R_{L}$, dado pela Equação 5 . O valor de $R_{L}$ indica a natureza da adsorção, a qual é desfavorável se $R_{L}>1$, linear se $R_{L}=1$, favorável se $0<\mathrm{R}_{\mathrm{L}}<1$, ou irreversível se $\mathrm{R}_{\mathrm{L}}=0$ (KARA, YILMAZER \& AKAR, 2017).

$\mathrm{R}_{\mathrm{L}}=\frac{1}{1+\mathrm{K}_{\mathrm{L}} \cdot \mathrm{Co}}$

Em que: $\mathrm{R}_{\mathrm{L}}$ é um parâmetro de equilíbrio; $\mathrm{K}_{\mathrm{L}}$ é a constante da isoterma de Langmuir (L.mg-1 ); C é a concentração inicial (mg.L $\left.{ }^{-1}\right)$.

O modelo multicamadas de Freundlich é normalmente utilizado para descrever as características de adsorção de uma superfície heterogênea. É representado pela Equação 6 (JAVADIAN et al., 2015).

$\mathrm{Q}_{\mathrm{e}}=\mathrm{K}_{\mathrm{f}} \mathrm{C}_{\mathrm{e}}^{1 / \mathrm{n}}$

Em que: $\mathrm{K}_{\mathrm{f}}$ é a constante da isoterma de Freundlich $\left(\mathrm{L}_{\mathrm{mg}} \mathrm{mg}^{-1}\right)$; n é a intensidade de adsorção (fator adimensional).

\section{Parâmetros termodinâmicos}

Os principais parâmetros termodinâmicos envolvidos no processo foram determinados, como variação de entalpia $\left(\Delta \mathrm{H}^{\circ}\right)$, variação de entropia $\left(\Delta \mathrm{S}^{\circ}\right)$ e variação da energia livre de Gibbs $\left(\Delta \mathrm{G}^{\mathrm{o}}\right)$. A variação da energia livre de Gibbs em J.mol ${ }^{-1}$ é calculada por meio da Equação 7 (LIU et al., 2016).

$\Delta \mathrm{G}^{\mathrm{o}}=-\mathrm{RT} \ln \mathrm{K}_{\mathrm{d}}$

Em que: $\Delta \mathrm{G}^{\circ}$ é a variação da energia livre de Gibbs; Ré a constante universal dos gases perfeitos, igual a 8,314 J.(mol.K) ${ }^{-1}$; Té a temperatura $(\mathrm{K})$; $\mathrm{K}_{\mathrm{d}}$ éo coeficiente de distribuição.

Os valores das variações de entalpia e entropia de adsorção em J.mol ${ }^{-1} \mathrm{e}$ $\mathrm{J}(\mathrm{mol} . \mathrm{K})^{-1}$, respectivamente, podem ser encontrados pela equação de Van't Hoff (Equação 8). No gráfico $\ln \mathrm{K}_{\mathrm{d}}$ versus $1 / \mathrm{T}, \Delta \mathrm{S} \%$ R é o intercepto da reta no eixo y e $-\Delta \mathrm{H}$ \%/RT será a sua inclinação. Dessa forma, pode-se determinar a variação da entalpia e entropia ( $\Delta \mathrm{H}^{\circ}$ e $\Delta \mathrm{S}^{\circ}$ ) (ABO-FARHA et al., 2009; LIU et al., 2016).

$\operatorname{Ln} K_{d}=\frac{-\Delta H^{\circ}}{R T}+\frac{\Delta S^{\circ}}{R}$

\section{RESULTADOS E DISCUSSÃO}

\section{Caracterização do geopolímero}

A composição química do adsorvente é apresentada na Tabela 2. Foi possível verificar a predominância da presença de $\mathrm{SiO}_{2}$ na composição do adsorvente, proveniente da CCA e do RC. A concentração de sódio (Na) obteve um valor intermediário, o que sugere que o $\mathrm{Na}$ livre observado no geopolímero antes da adsorção pode ser lixiviado à solução. Já o Na remanescente pode agir como um cátion de balanceamento de carga, à rede de aluminossilicatos carregados negativamente, permitindo a adsorção de espécies metálicas (NOVAIS et al., 2019).

Outros adsorventes também têm a $\mathrm{SiO}_{2}$ como componente majoritário, assim como potássio (K) e Mg como elementos traço. No estudo apresentado por Barros et al. (2001), o adsorvente de argila ativada contém Al como um dos componentes majoritários em razão da presença de cerâmica em sua constituição, coincidindo com o adsorvente em estudo.

A Figura 1 mostra as características morfológicas do geopolímero. As micrografias revelaram que o geopolímero apresenta uma estrutura heterogênea, típica de geopolímeros à base de cinzas (IZQUIERDO et al., 2009; SIYAL et al., 2016). Constatou-se a presença de porosidade de, aproximadamente, $12 \%$. A área superficial reportada pelo BET foi de $42,99 \mathrm{~m}^{2} / \mathrm{g}^{-1}$. Singhal et al. (2017) comentam que a porosidade favorece o processo de adsorção e está diretamente associada com a área superficial e com a capacidade de adsorção dos diferentes adsorventes.

Kara, Yilmazer e Akar (2017) utilizaram geopolímero à base de metacaulim como adsorvente e encontraram uma área superficial semelhante, com um valor de 39,42 $\mathrm{m}^{2} \cdot \mathrm{g}^{-1}$, a qual demonstrou ser eficiente na remoção de $\mathrm{Zn}$ e Ni de soluções aquosas. Jeremias (2019) encontrou uma área inferior de 5,69 $\mathrm{m}^{2} \cdot \mathrm{g}^{-1}$ na pesquisa realizada para adsorção de Fe de água contaminada pela DAM utilizando casca de ovo como adsorvente. Ahmaruzzaman (2011) explica que a capacidade de adsorção dos resíduos depende muito da área de superfície específica disponível para a interação superfície/soluto. O estudo de difusão intrapartícula mostra que o tamanho das partículas dos materiais dos resíduos usados influencia na taxa de adsorção. Diminuindo o tamanho da partícula, aumentam-se a área de superfície e a adsorção. Devido a vários fatores, como resistência à transferência de massa, tempo de contato e bloqueio de algum caminho de difusão, a maior parte da superfície interna da partícula não pode ser utilizada para adsorção, o que diminui a eficiência do processo.

\section{Caracterização da água impactada com a drenagem ácida de mina}

A caracterização da água contaminada com a DAM resultou em uma concentração total de Fe igual a 31,06 mg. $\mathrm{L}^{-1}$. Esse valor é superior ao estipulado pelas Resoluções do Conselho Nacional do Meio Ambiente (CONAMA) no 357 de 17 de março de 2005 (águas doces de Classe 3) e n ${ }^{\circ} 430$ de 13 de maio de 2011 (efluentes), em que o valores máximos permitidos são de 5,0 $\mathrm{g} \mathrm{L}^{-1} \mathrm{e} 15 \mathrm{~g} \mathrm{~L}^{-1}$, respectivamente. $\mathrm{O}$ valor do $\mathrm{pH}$ obtido foi de 3,1 , característico de águas afetadas pela DAM (HEDIN et al., 2010). Quando comparado à legislação, que requer valores entre 5,0 e 9,0, o pH encontrado no presente estudo é considerado muito baixo. Isso favorece a dissolução de metais presentes nas rochas do leito do rio e a precipitação de elementos químicos tóxicos.

Tabela 2 - Composição química dos geopolímeros.

\begin{tabular}{c|c|c|c|c|c|c|c|c|c|c|c|c}
\multicolumn{7}{c}{ Composição (m\%) } \\
$\mathrm{Al}_{2} \mathrm{O}_{3}$ & $\mathrm{CaO}$ & $\mathrm{Fe}_{2} \mathrm{O}_{3}$ & $\mathrm{~K} / \mathrm{O}$ & $\mathrm{MgO}$ & $\mathrm{MnO}$ & $\mathrm{Na}_{2} \mathrm{O}$ & $\mathrm{P}_{2} \mathrm{O}_{5}$ & $\mathrm{SiO}_{2}$ & $\mathrm{TiO}_{2}$ & $\mathrm{Pl}^{*}$ \\
\hline 14,23 & 3,71 & 0,37 & 1,10 & 1,59 & 0,05 & 24,22 & 0,38 & 49,48 & 0,18 & 4,68 \\
\hline
\end{tabular}

*Pl: perda por ignição em $960^{\circ} \mathrm{C}$

Fonte: elaborada pelos autores. 
A acidez e a elevada concentração de Fe nas amostras de água podem estar associadas à contaminação com as drenagens. As drenagens de mina podem ser formadas pela percolação de aquíferos em minerais sulfetados, entre os quais destaca-se $\mathrm{FeS}_{2}$. Quando exposta ao ar e à água, a $\mathrm{FeS}_{2}$ é oxidada e dissociada, liberando $\mathrm{Fe}^{2+}$ em solução, que pode ser rapidamente oxidado a $\mathrm{Fe}^{3+}$ e precipitado na forma de hidróxidos. Depois de iniciada a reação é desencadeado um ciclo, em que o $\mathrm{Fe}^{2+}$ é oxidado a $\mathrm{Fe}^{3+}$ e, subsequentemente, reduzido pela $\mathrm{FeS}_{2}$, liberando $\mathrm{Fe}^{2+} \mathrm{e}$ acidez adicional, conforme demonstrado nas Equações 9 a 12 (FUNGARO \& IZIDORO, 2006; PARK et al., 2019).

$4 \mathrm{FeS}_{2}(\mathrm{~s})+14 \mathrm{O}_{2}(\mathrm{~g})+12 \mathrm{H}_{2} \mathrm{O}(\mathrm{l}) \rightleftarrows 4 \mathrm{Fe}^{2+}+8 \mathrm{SO}_{4}^{2-}+8 \mathrm{H}_{3} \mathrm{O}^{+}$
$4 \mathrm{Fe}^{2+}+8 \mathrm{H}_{3} \mathrm{O}^{+}+2 \mathrm{O}_{2}(\mathrm{~g}) \rightleftarrows 4 \mathrm{Fe}^{3+}+12 \mathrm{H}_{2} \mathrm{O}(\mathrm{l})$

$4 \mathrm{Fe}^{3+}+24 \mathrm{H}_{2} \mathrm{O}(\mathrm{l}) \rightleftarrows 4 \mathrm{Fe}(\mathrm{OH})_{3}(\mathrm{~s})+12 \mathrm{H}_{3} \mathrm{O}^{+}$

$\mathrm{FeS}_{2}(\mathrm{~s})+14 \mathrm{Fe}^{3+}+24 \mathrm{H}_{2} \mathrm{O}(\mathrm{l}) \rightleftarrows 15 \mathrm{Fe}^{2+}+2 \mathrm{SO}_{4}^{2-}+16 \mathrm{H}_{3} \mathrm{O}^{+}$

\section{Efeito da dosagem de adsorvente}

$\mathrm{O}$ efeito da quantidade de geopolímero na adsorção de íons Fe foi avaliado em relação à eficiência de remoção e capacidade de adsorção, para determinar a dose ideal de adsorvente. Os resultados são mostrados na Figura 2.
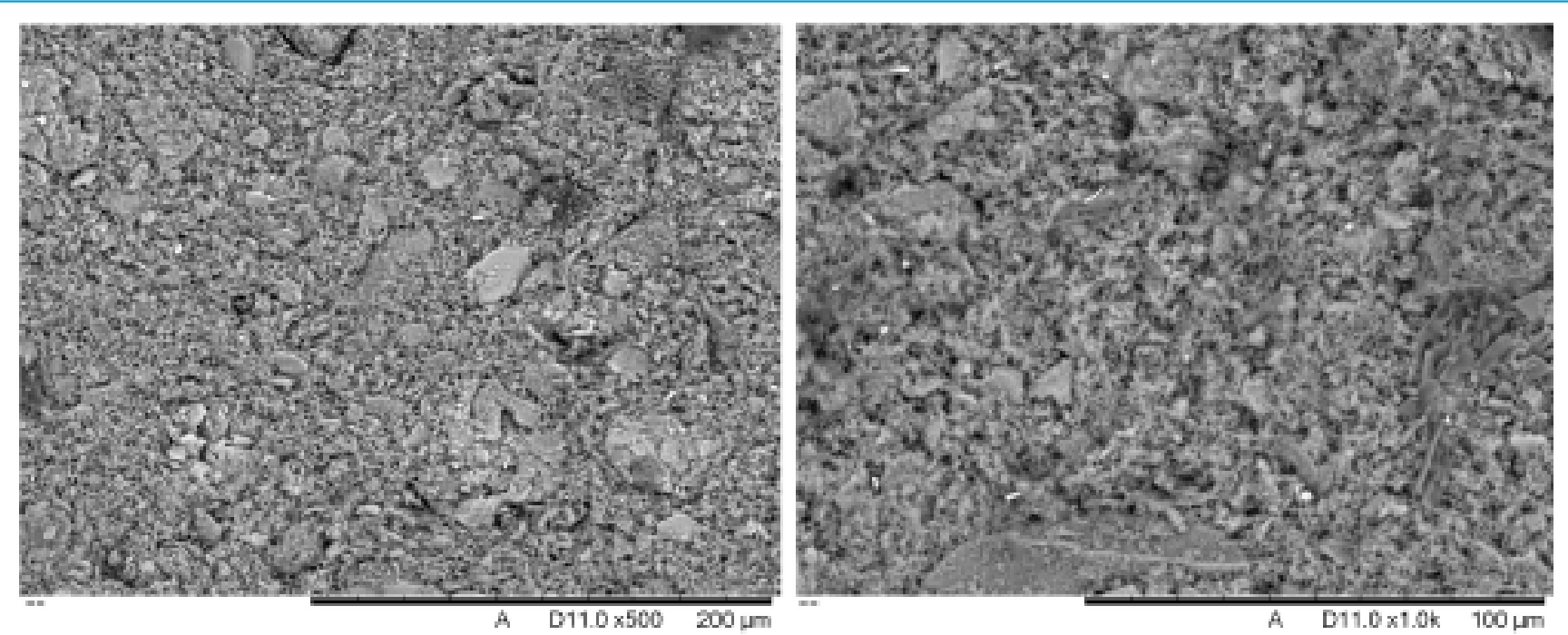

Fonte: elaborada pelos autores

Figura 1 - Micrografia do adsorvente geopolimérico baseado em cinza da casca de arroz e resíduo cerâmico.

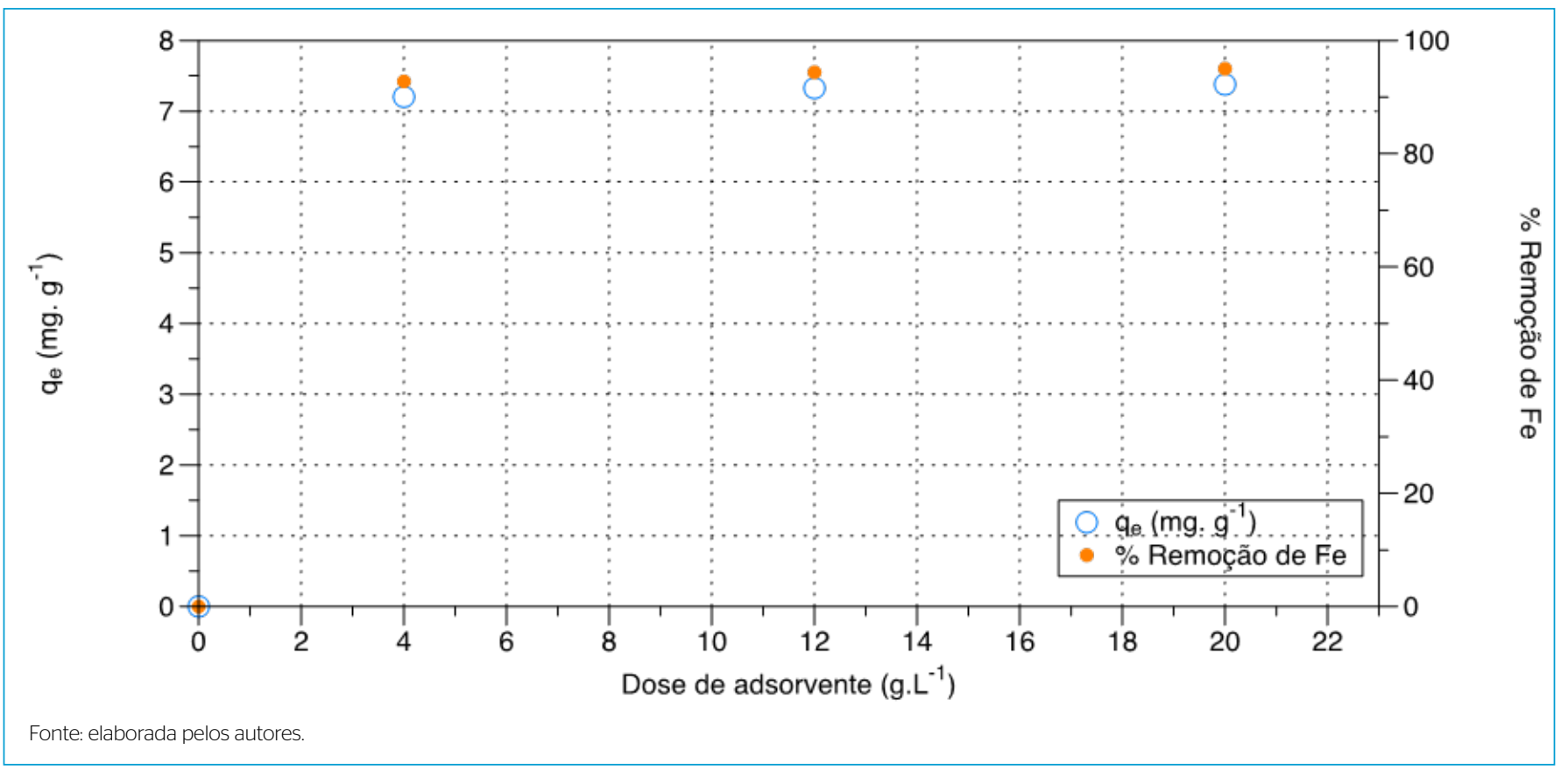

Figura 2 - Efeito da quantidade de adsorvente na capacidade de adsorção e na eficiência de remoção de ferro. 
Observou-se que a eficiência de remoção do metal aumentou com a elevação da dosagem de adsorvente, com valores de 93, 94 e $95 \%$ de remoção, para as dosagens de $4 \mathrm{~g} \mathrm{~L}^{-1}, 12 \mathrm{~g} \mathrm{~L}^{-1}$ e $20 \mathrm{~g} \mathrm{~L}^{-1}$, respectivamente. O aumento da quantidade de adsorvente amplia o número de sítios de adsorção disponíveis e, portanto, a quantidade de Fe adsorvido. A mesma tendência foi observada quando se avaliou a capacidade de adsorção de Fe no geopolímero.

Alguns autores, em seus ensaios para a remoção de Fe de soluções aquosas, utilizaram valores diferentes, como Furlan et al. (2017), o qual utilizou uma dosagem de $2 \mathrm{~g} \mathrm{~L}^{-1}$ e atingiu 96\% de remoção de Fe. Jeremias (2019) aplicou uma dosagem de $10 \mathrm{~g} \mathrm{~L}^{-1}$ e conseguiu remover cerca de $99 \%$ de Fe no período de contato de $2.880 \mathrm{~min}$.

No presente estudo, o $\mathrm{pH}$ da solução foi monitorado e apresentou um aumento desse parâmetro. Em dosagens de $4 \mathrm{~g} \mathrm{~L}^{-1}$, o pH obtido foi de 10,2 e, em dosagens de $20 \mathrm{~g} \mathrm{~L}^{-1}, \mathrm{o} \mathrm{pH}$ foi de 11,2. Esse valor está fortemente relacionado à presença de $\mathrm{NaOH}$ na composição do adsorvente, já que é uma base forte. O valor ultrapassa o estabelecido pela legislação. Porém, existe a possibilidade de correção desse perfil ao se alterar a proporção sólido/líquido do geopolímero. Uma alternativa é utilizar o geopolímero diretamente na DAM em que o pH é ainda inferior a 3,1, reportado neste estudo.

Segundo Weiler, Amaral e Schneider (2016), o pH ideal para a precipitação dos hidróxidos metálicos varia de acordo com o tipo de metal. $\mathrm{O} \mathrm{Fe}^{3+}$ precipita em $\mathrm{pH}$ acima de 3,5 e o $\mathrm{Fe}^{2+} \mathrm{em} \mathrm{pH}$ superior a 8,0. Outros íons presentes na DAM, como o $\mathrm{Al}^{3+}$, precipitam entre valores de $\mathrm{pH} 4,5$ e 9,0, e o $\mathrm{Mn}^{2+}$, em pH acima de 8,5. Assim, na maioria das estações de tratamento considera-se que o valor ideal de ajuste do $\mathrm{pH}$ fica entre 8,5 e 8,7. Nessa condição, todos os metais precipitam e o efluente se enquadra na faixa de $\mathrm{pH}$ entre 5,0 e 9,0, prevista na Resolução do CONAMA 430/2011.
Em todos os testes, a dosagem de adsorvente usada foi de $4 \mathrm{~g} \mathrm{~L}^{-1}$, em que os valores de $\mathrm{pH}$ não sofreram alteração significativa, permanecendo na faixa de $10,2-10,85$.

\section{Cinética de adsorção}

$\mathrm{O}$ efeito do tempo de contato na adsorção de $\mathrm{Fe}$ foi determinado entre $10 \mathrm{e}$ 60 min, e os resultados são apresentados na Figura 3. Os resultados mostram que a adsorção foi rápida nos primeiros $10 \mathrm{~min}$, atingindo o equilíbrio em aproximadamente $20 \mathrm{~min}$, com valores de capacidade de adsorção no equilíbrio $\left(\mathrm{q}_{\mathrm{e}}\right)$ de 7,18 e $7,15 \mathrm{mg} \cdot \mathrm{g}^{-1}$, respectivamente.

O comportamento da adsorção em relação ao tempo é semelhante ao encontrado por Kara, Yilmazer e Akar (2017), em que a adsorção de metais Zn e Ni foi rápida e aconteceu, praticamente, nos primeiros $20 \mathrm{~min}$. O efeito do tempo de contato na adsorção de $\mathrm{Zn}$ e Ni foi determinado entre 5 e $90 \mathrm{~min}$, e o tempo de equilíbrio entre 40 e $50 \mathrm{~min}$, com valores de $\mathrm{q}_{e}$ iguais a 60,06 e 29,40 $\mathrm{mg} . \mathrm{g}^{-1}$ para $\mathrm{Zn}$ e Ni, respectivamente. Esses valores são superiores aos obtidos na presente pesquisa. $\mathrm{O}$ baixo valor de $\mathrm{q}_{\mathrm{e}}$ pode estar relacionado à presença de outros elementos, além de Fe na água impactada pela DAM, pois trata-se de uma amostra com multicomponentes. Isso implica disputa pelos sítios ativos do adsorvente. No entanto, o valor de $\mathrm{q}_{\mathrm{e}}$ é superior ao obtido por Ferro (2018), na adsorção de índigo-carmim em adsorvente geopolimérico de CCA, em que o valor de $\mathrm{q}_{\mathrm{e}}$ foi de $1,866 \mathrm{mg} \cdot \mathrm{g}^{-1}$ para o melhor resultado encontrado.

Tabela 3 - Parâmetros cinéticos de adsorção de ferro em adsorvente geopolimérico.

\begin{tabular}{|l|c|c|c|c|c|}
\multicolumn{3}{c|}{ Modelo de pseudoprimeira ordem } & \multicolumn{3}{c|}{ Modelo de pseudos segunda ordem } \\
\hline $\mathrm{q}_{\mathrm{e}}\left(\mathrm{mg} \mathrm{g}^{-1}\right)$ & $\mathrm{K}_{1}\left(\mathrm{~min}^{-1}\right)$ & $\mathrm{R}^{2}$ & $\mathrm{q}_{\mathrm{e}}\left(\mathrm{mg} \mathrm{g}^{-1}\right)$ & $\mathrm{K}_{2}\left(\mathrm{~g} \cdot \mathrm{mg}^{-1} \mathbf{m i n}^{-1}\right)$ & $\mathrm{R}^{2}$ \\
\hline 719 & 0.0004 & 0.9286 & 703 & 0.82 & 0.99997 \\
\hline
\end{tabular}

Fonte: elaborada pelos autores

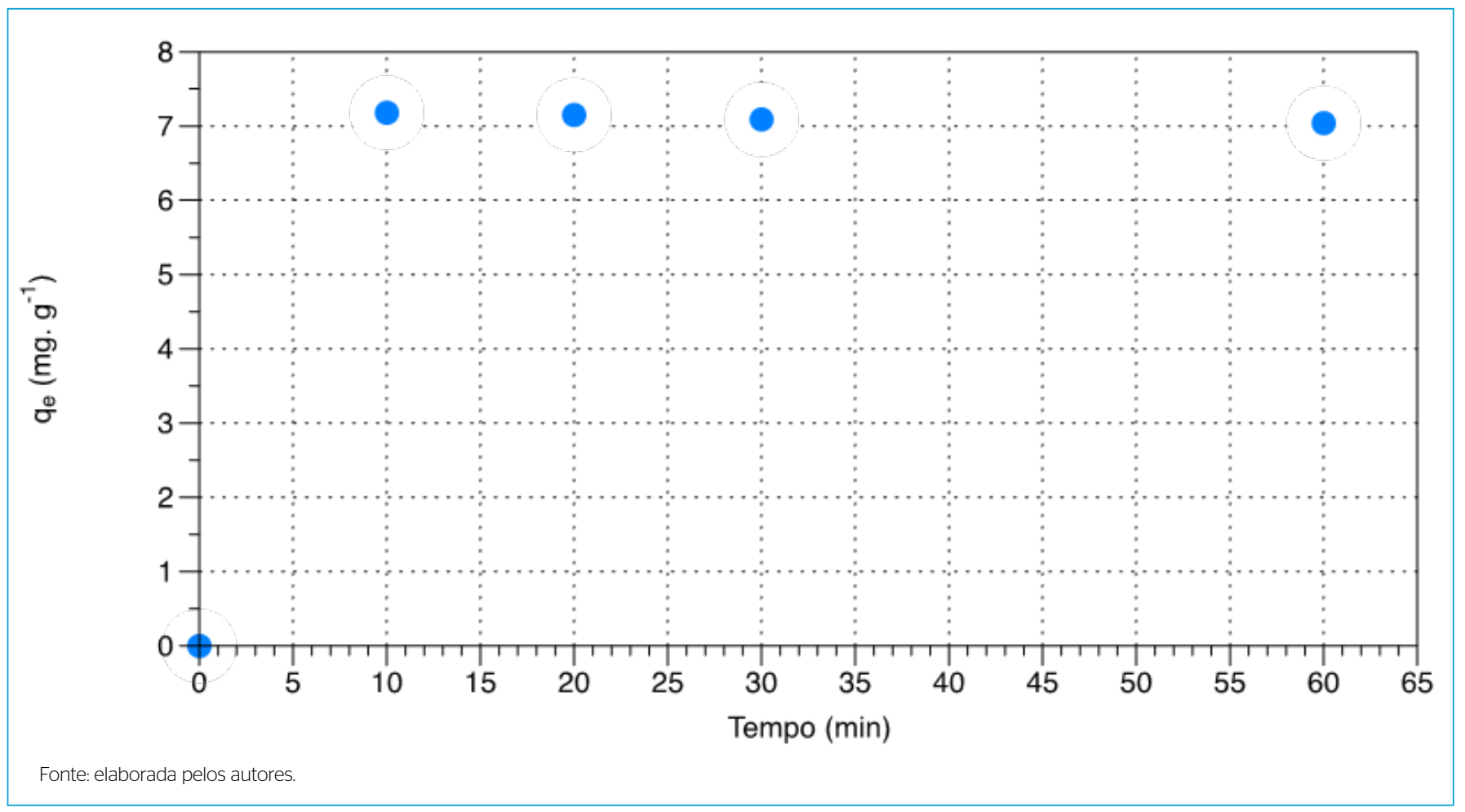

Figura 3 - Efeito do tempo de contato em relação à capacidade de adsorção de ferro dos geopolímeros baseados em cinza da casca de arroz e resíduo cerâmico. 
Os parâmetros dos modelos cinéticos obtidos por regressão linear são apresentados na Tabela 3. Os melhores ajustes (valores de $\mathrm{R}^{2}$ ) foram obtidos com o modelo cinético de pseudossegunda ordem, indicando que, possivelmente, o processo de sorção de Fe pelo geopolímero é governado por quimissorção. Segundo Runtti et al. (2014), a primeira fase de sorção relaciona-se à ocupação dos íons Fe nos locais de superfície mais prontamente disponíveis, enquanto as últimas fases envolvem a difusão lenta do adsorvato da superfície até os poros internos.

\section{Efeito da temperatura e isotermas de adsorção}

A fim de investigar o efeito da temperatura na adsorção de $\mathrm{Fe}$, experimentos de adsorção foram realizados em diferentes temperaturas (298, 303 e 308 K) e concentrações iniciais da água impactada pela $\operatorname{DAM}(25,50,75$ e 100\%), uma vez que a temperatura pode interferir na energia cinética das moléculas do sistema e, também, nas forças de atração e repulsão entre o adsorvato e $\mathrm{o}$ adsorvente. A relação entre a temperatura, os valores de $\mathrm{q}_{e}$ e a concentração inicial da AIDAM é ilustrada na Figura 4.

De acordo com a Figura 4, com o aumento da temperatura, percebe-se uma elevação da capacidade de adsorção do geopolímero, que é mais evidente nas concentrações inicias de água impactada pela $\operatorname{DAM}(25,50$ e 75\%). Em sua maior concentração inicial (100\%), a capacidade de adsorção permaneceu quase a mesma. Esse fato depende muito da natureza do processo de adsorção (endotérmico ou exotérmico), e, ainda, a partir de certo valor de temperatura, a dessorção do adsorvato começa a ser considerada. Segundo Soliman e Moustafa (2020), quando o processo de adsorção apresenta caráter exotérmico, o aumento da temperatura afeta a força de adsorção entre os sítios ativos e as moléculas adsorvidas, o que deve resultar em uma diminuição na capacidade de sorção. No entanto, o processo de difusão é considerado um processo endotérmico e, portanto, se o processo de adsorção ao longo do tempo de reação for controlado em alguma extensão por etapas de difusão intrapartículas, a capacidade de adsorção deve mostrar um aumento com a temperatura (WORCH, 2012). Um aumento na temperatura da solução pode levar a um aumento na mobilidade dos íons metálicos presentes na água impactada pela DAM, podendo as forças de retardamento que atuam nos íons difusores também diminuir (MANE et al., 2006). Para Ahmaruzzaman (2011), as concentrações iniciais de metais têm um forte efeito sobre a capacidade de adsorção de diversos resíduos industriais e, de um modo geral, a capacidade de adsorção acresce com o aumento das concentrações iniciais dos metais pesados. A concentração inicial proporciona uma força motriz importante para superar toda a resistência de transferência de massa de metais pesados entre as fases aquosas e sólidas.

Os dados da adsorção de Fe no geopolímero em condições isotérmicas foram modelados através das isotermas de Langmuir e Freundlich. Os parâmetros, bem como seus coeficientes de correlação $\left(R^{2}\right)$, são apresentados na Tabela 4. A isoterma que mostrou melhor ajuste para descrever a adsorção de Fe no geopolímero foi a de Langmuir. Os valores de $\mathrm{R}^{2}$ estão mais próximos da unidade que os encontrados na isoterma de Freundlich, indicando, provavelmente, que a adsorção ocorreu na superfície de forma homogênea, com forte interação entre o Fe e o geopolímero. Para Maleki et al. (2020), neste modelo

Tabela 4 - Parâmetros das isotermas de adsorção de ferro da água impactada pela drenagem ácida de mina no geopolímero.

\begin{tabular}{l|c|c|c}
\multicolumn{4}{c}{ Isoterma de Langmuir } \\
\hline & $298 \mathrm{~K}$ & $303 \mathrm{~K}$ & $308 \mathrm{~K}$ \\
\hline $\mathrm{q}_{\mathrm{m}}\left(\mathrm{mg}^{-1}\right)$ & 1,175 & 1,563 & 1,086 \\
\hline $\mathrm{K}_{\mathrm{L}}\left(\mathrm{L} \cdot \mathrm{mg}^{-1}\right)$ & 0,425 & 0,552 & 1,855 \\
\hline $\mathrm{R}_{\mathrm{L}}$ & 0,07 & 0,06 & 0,02 \\
\hline $\mathrm{R}^{2}$ & 0,9986 & 0,9745 & 0,9638 \\
\hline $\mathrm{K}_{\mathrm{f}}\left(\mathrm{L} . \mathrm{mg}^{-1}\right)$ & Isoterma de Freundlich & \\
\hline $1 / \mathrm{n}_{\mathrm{F}}$ & 93,41 & 24,12 & 3,217 \\
\hline $\mathrm{R}^{2}$ & 2,5387 & 1,5426 & 0,9449 \\
\hline
\end{tabular}

Fonte: elaborada pelos autores.

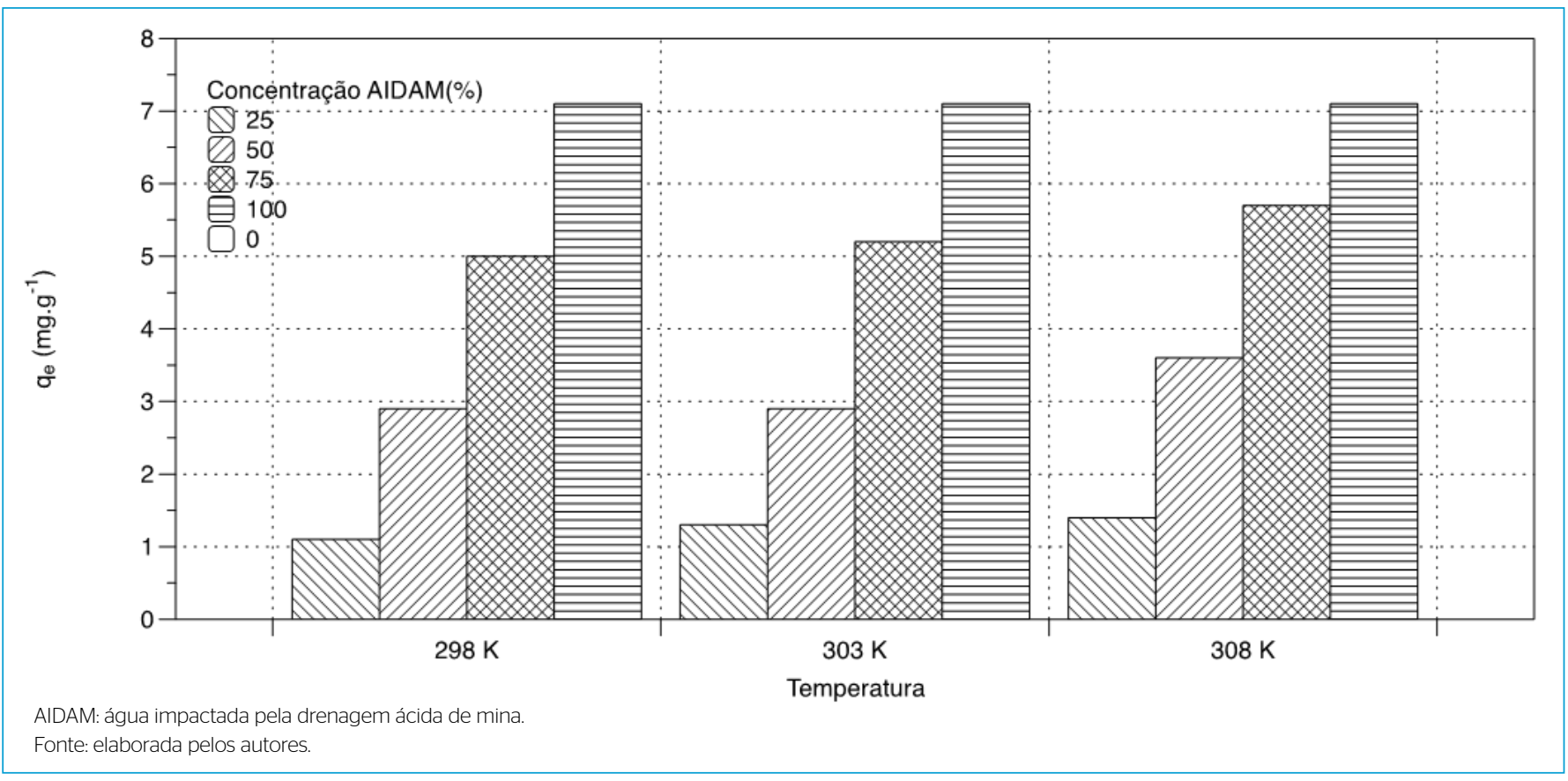

Figura 4 - Efeito da temperatura na capacidade de adsorção de ferro no geopolímero baseado em cinza da casca de arroz e resíduo cerâmico. 
ocorre apenas a cobertura superficial da monocamada, sendo todos os locais da superfície equivalentes e as moléculas adsorvidas imóveis. De acordo com

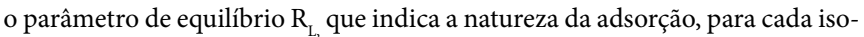
terma avaliada, a adsorção de Fe no geopolímero foi considerada favorável, já que $0<\mathrm{R}_{\mathrm{L}}<1$ (KARA, YILMAZER \& AKAR, 2017).

Por outro lado, o modelo de Freundlich permitiu observar, através do parâmetro $1 / \mathrm{n}_{\mathrm{F}}$ que a adsorção de Fe no geopolímero é, principalmente, cooperativa $\left(1 / n_{\mathrm{F}}>1\right)$, em que acontece tanto a fisissorção como a quimissorção. Aumentando a temperatura para $308 \mathrm{~K}$, a adsorção, nesse caso, torna-se favorável. Como foi discutido anteriormente, isso acontece, provavelmente, pela difusão dos íons metálicos no adsorvente, a qual é favorecida com o aumento da temperatura.

\section{Parâmetros termodinâmicos}

A partir das isotermas de Langmuir, foram calculados os parâmetros termodinâmicos $\Delta \mathrm{G}^{\circ}, \Delta \mathrm{H}^{\circ}$ e $\Delta \mathrm{S}^{\circ}$, mostrados na Tabela 5. (Tabela 5)

De acordo com a Tabela 5 , valores negativos para $\Delta \mathrm{G}^{\circ}$ acompanhados de valores positivos para $\Delta S^{\circ}$ indicam que o processo de adsorção do Fe da água impactada pela DAM nos geopolímeros foi espontâneo. $\mathrm{O}$ valor positivo de $\Delta \mathrm{H}^{\circ}$ sugere que o fenômeno de adsorção é endotérmico, enquanto os valores positivos de $\Delta \mathrm{S}^{\circ}$ refletem uma organização mais aleatória do adsorvato na interface sólido/solução durante o processo de adsorção.

A capacidade de adsorção de íons Fe observados nos testes cinéticos, isotérmicos e termodinâmicos pode estar relacionada à presença dos óxidos encontrados na estrutura do adsorvente geopolimérico ( $\mathrm{Ex}: \mathrm{SiO}_{2}, \mathrm{NaO}_{2}, \mathrm{Al}_{2} \mathrm{O}_{3}$ e CaO). Tem-se proposto que esses óxidos, em meio aquoso, apresentam as superfícies recobertas por camadas de grupos hidroxil (S-OH), conferindo propriedades doadoras similares aos solutos correspondentes dissolvidos, como hidróxidos e carboxilatos. Essas propriedades possibilitam a ocorrência de equilíbrios de adsorção com metais (Equações 13, 14 e 15), com consequente remoção destes em solução (DZOMBAK \& MOREL, 1990).

$$
\begin{aligned}
& \mathrm{S}-\mathrm{OH}+\mathrm{M}^{\mathrm{z}} \rightleftarrows \mathrm{S}-\mathrm{OM}^{(\mathrm{z}-1)+}+\mathrm{H}^{+} \\
& 2 \mathrm{~S}-\mathrm{OH}+\mathrm{M}^{\mathrm{z}} \rightleftarrows(\mathrm{S}-\mathrm{O})_{2} \mathrm{M}^{(\mathrm{z}-2)+}+2 \mathrm{H}^{+} \\
& \mathrm{S}-\mathrm{OH}+\mathrm{M}^{\mathrm{z}}+\mathrm{H}_{2} \mathrm{O} \rightleftarrows \mathrm{S}-\mathrm{OMOH}^{(\mathrm{z}-2)+}+2 \mathrm{H}^{+}
\end{aligned}
$$

Tabela 5 - Parâmetros termodinâmicos da adsorção de ferro da água impactada pela drenagem ácida de mina no geopolímero.

\begin{tabular}{l|c|c|c} 
Temperatura (K) & $\Delta \mathrm{G}\left(\mathrm{J}_{\mathrm{mol}} \mathbf{1}^{-1}\right)$ & $\Delta \mathrm{H}\left(\mathrm{KJ} \cdot \mathrm{mol}^{-1}\right)$ & $\Delta \mathrm{S}\left(\mathrm{J} .(\mathrm{mol} . \mathrm{K})^{-1}\right)$ \\
\cline { 1 - 2 } 298 & $-34911,6$ & & \\
\cline { 1 - 2 } 303 & $-36156,0$ & \multirow{2}{*}{112,04} & 491,78 \\
\hline 308 & $-39856,5$ & & \\
\hline
\end{tabular}

Fonte: elaborada pelos autores.
A remoção de Fe poderia ser também decorrente da adsorção dos íons $\mathrm{H}_{3} \mathrm{O}^{+}$ em solução pelos óxidos do adsorvente, o que conduziria à elevação do $\mathrm{pH}$, com consequente formação e precipitação de óxido e/ou hidróxidos insolúveis do metal. O grupo hidroxil exibe um comportamento como base de Lewis, e, portanto, a adsorção dos íons $\mathrm{H}_{3} \mathrm{O}^{+}$envolveria a protonação dos grupos hidroxil da superfície do adsorvente (Equação 16) (DZOMBAK \& MOREL, 1990).

$\mathrm{S}-\mathrm{OH}+\mathrm{H}_{3} \mathrm{O}^{+} \rightleftarrows \mathrm{S}-\mathrm{OH}_{2}^{+}+\mathrm{H}_{2} \mathrm{O}$

Além disso, é possível que os íns metálicos estejam sendo removidos por adsorção aos óxidos, através de interação por complexação, formação de par iônico, troca iônica, interação eletrostática, forças de Van der Walls, entre outros mecanismos (WU et al., 2004).

\section{CONCLUSÃO}

A remoção de Fe em água impactada com a DAM utilizando geopolímero constituído de RC e CCA como material adsorvente foi investigada sob diversas condições. A condição mais favorável, considerando as alterações nos valores de $\mathrm{pH}$, alcançou capacidade máxima de adsorção de Fe pelo geopolímero com uma dose de adsorvente de 4,0 $\mathrm{g} \mathrm{L}^{-1}$, em um tempo de contato de $20 \mathrm{~min}$, à temperatura de $25{ }^{\circ} \mathrm{C}$, obtendo-se remoções de até, aproximadamente, $93 \%$. O valor do $\mathrm{pH}$ foi elevado de 3,1 para 10,2. Os estudos cinéticos apresentaram coeficiente de correlação mais próximo da unidade para o modelo cinético de pseudossegunda ordem, indicando que o processo ocorreu por quimissorção. Os resultados do efeito da temperatura na capacidade de adsorção de Fe mostraram que esta obteve um leve aumento da eficiência de remoção em temperaturas maiores para uma mesma concentração inicial de água impactada pela DAM. Diminuindo a concentração inicial, a capacidade de adsorção de Fe foi reduzida. Os dados de adsorção no equilíbrio foram adequadamente representados pela isoterma de adsorção de Langmuir, indicando uma adsorção em monocamada. Os parâmetros termodinâmicos indicaram que o processo de adsorção é endotérmico e espontâneo. A capacidade de remoção de Fe em solução pode ser decorrente do equilíbrio de adsorção com metais e ácido-básico, promovidos pelos óxidos constituintes do geopolímero. Os resultados obtidos no presente estudo apontam que o uso do adsorvente com base em RC e CCA tem boa perspectiva para a remoção de $\mathrm{Fe}$ em mananciais contaminados com drenagem ácida de minas.

\section{CONTRIBUIÇÃO DOS AUTORES}

Wesler, S.: elaboração dos ensaios experimentais, análise de dados. Brida, I. C.: escrita primeira redação. Geremias, R.: revisão, supervisão e edição. Menezes, C. T. B.: revisão, supervisão e edição. Pineda-Vasquez, T.: conceituação, supervisão, escrita, revisão e edição.

\section{REFERÊNCIAS}

ABO-FARHA, S. A.; ABDEL-AAL, A.Y;; ASHUOR, I. A.; GARAMON, S. E. Removal of some heavy metal cations by synthetic resin purolite C100. Journal of Hazardous Materials, v. 169, n. 1-3, p. 190-194, 2009. https://doi.org/10.1016/j. jhazmat.2009.03.086
AL-HARAHSHEH, M. S.; AL ZBOON, K.; AL-MAKHADMEH, L.; HARARAH, M.; MAHASNEH, M. Fly ash based geopolymer for heavy metal removal: a case study on copper removal. Journal of Environmental Chemical Engineering, v. 3, n. 3, p. 1669-1677, 2015. https://doi.org/10.1016/j.jece.2015.06.005 
ASIM, N.; ALGHOUL, M.; MOHAMMAD, M.; AMIN, M. H.; AKHTARUZZAMAN, M.; AMIN, N.; SOPIAN, K. Emerging sustainable solutions for depollution: geopolymers. Construction and building materials, v. 199, p. 540-548, 2019. http://doi.org/10.1016/j.conbuildmat.2018.12.043

BAI, C.; COLOMBO, P. Processing, properties and applications of highly porous geopolymers: a review. Ceramics International, v. 44, n. 14, p. 1610316118, 2018. http://doi.org/10.1016/j.ceramint.2018.05.219

BARROS, A. Remoção de íns metálicos em água utilizando diversos adsorventes. Dissertação (Mestrado em Engenharia Química) Universidade Federal de Santa Catarina, Florianópolis, 2001.

BRASIL. Resolução no 357, de 17 de março de 2005. Dispõe sobre a classificação dos corpos de água e diretrizes ambientais para o seu enquadramento, bem como estabelece as condições e padrões de lançamento de efluentes. Diário Oficial da União, Brasília, 2005.

BRASIL. Resolução no 430, de 13 de maio de 2011. Dispõe sobre as condições e padrões de lançamento de efluentes, complementa e altera a resolução no 357, de 17 de março de 2005, do Conselho Nacional do Meio Ambiente (CONAMA). Diário Oficial da União, Brasília, 2011.

DZOMBAK, D. A.; MOREL, F. M. M. surface complexation modeling: hydrons ferric oxide. New York: Wiley-Interscience, 1990. 416 p.

FERRO, J. K. C. Indigo carmine removed using geopolymers from rice husk ash as adsorbent. Trabalho de Conclusão de Curso (Graduação em Engenharia de Energia) - Universidade Federal de Santa Catarina, Araranguá, 2018.

FONTANA, I.; PETERSON, M.; CECHINEL, M. Application of brewing waste as biosorbent for the removal of metallic ions present in groundwater and surface waters from coal regions. Journal of Environmental Chemical Engineering, v. 6, n. 1, p. 660-670, 2018. http://doi.org/10.1016/j.jece.2018.01.005

FUNGARO, D. A.; IZIDORO, J. D. C. Remediação de drenagem ácida de mina usando zeólitas sintetizadas a partir de cinzas leves de carvão. Química Nova, v. 29, n. 4, p. 735-740, 2006. https://doi.org/10.1590/SO100-40422006000400019

FURLAN, F. L. Uso de subprodutos de milho, soja e trigo como adsorvente de ferro e manganês em sistema aquoso. Dissertação (Mestrado) Universidade Tecnológica Federal do Paraná, Campo Mourão, 2017.

GENTY, T.; BUSSIËRE, B.; PARADIE, M.; NECULITA, C. M. Passive biochemical treatment of ferri ferous mine drainage: Lorraine mine site, northern Quebec, Canadá. In: PROC. OF THE INTERNATIONAL MINE WATER ASSOCIATION (IMWA). Mining Meets Water - Conflicts and Solutions. Freiberg, Germany: TU Bergakademie Freiberg, 2016.

HE, X.; YAO, B.; XIA, Y.; HUANG, H.; GAN, Y.; ZHANG, W. Coal fly ash derived zeolite for highly efficient removal of $\mathrm{Ni}^{2+}$ inwaste water. Powder technology, v. 367, p. 40-46, 2020. https://doi.org/10.1016/j.powtec.2019.11.037

HEDIN, R.; WEAVER, T:; WOLFE, N.; WEAVER, K. Passive Treatment of Acidic Coal Mine Drainage: The Anna S Mine Passive Treatment Complex. Mine Water and the Environment, v. 29, n. 3, p.165-175, 2010. http://doi.org/10.1007/s10230-010-0117-1

HO, Y. S.; MCKAY, G. Pseudo-second order model for sorption processes. Process biochemistry, v. 34, n. 5, p. 451-465, 1999. https://doi.org/10.1016/ S0032-9592(98)00112-5

IZQUIERDO, M.; QUEROL, X.; DAVIDOVITS, J.; ANTENUCCI, D.; NUGTEREN, H.; FERNÁNDEZ-PEREIRA, C. Coal fly ash-slag-based geopolymers: microstructure and metal leaching. Journal of Hazardous Materials, v. 166, n. 1, p. 561-566, 2009. https://doi.org/10.1016/j.jhazmat.2008.11.063
JAVADIAN, H.; GHORBANI, F.; TAYEBI, H. A.; ASL, S. M. H. Study of the adsorption of $\mathrm{Cd}$ (ii) from aqueous solution using zeolite- based geopolymer, synthesized from coal fly ash, kinetic, isotherm and thermodynamic studies. Arabian Journal of Chemistry, v. 8, n. 6, p. 837-849, 2015. https://doi.org/10.1016/j.arabjc.2013.02.018

JEREMIAS, T. C. Estudo do potencial de biossorventes de baixo custo para remediação de águas fluviais contaminadas com drenagem ácida de mina (DAM), visando seu reuso secundário não potável. Dissertação (Mestrado em Energia e Sustentabilidade) - Universidade Federal de Santa Catarina, Araranguá, 2019.

JEREMIAS, T; PINEDA-VÁSQUES, T: LOBO-RECIO, M. Utilização de cinza da casca do arroz como biossorvente na remediação de águas fluviais impactadas por drenagem ácida mineral. In: Simpósio de Integração Científica e Tecnológica do Sul Catarinense - 70 SICT, Araranguá, 2018. Anais [...]. Araranguá: Instituto Federal de Santa Catarina, 2018. Disponível em: http://eventoscientificos.ffsc edu.br/index.php/sictsul/7-sict-sul/paper/view/2496. Acesso em: 20 out. 2019.

JOHNSON, D. B.; HALLBERG, K. B. Acid mine drainage remediation options: a review. Science of the Total Environment, v. 338, n. 1-2, p. 3-14, 2005. https:// doi.org/10.1016/j.scitotenv.2004.09.002

KARA, I.; YILMAZER, D.; AKAR, S. T. Metakaolin based geopolymer as an effective adsorbent for adsorption of zinc (ii) and nickel (ii) ions from aqueous solutions. Applied Clay Science, v. 139, p. 54-63, 2017. https://doi. org/10.1016/j.clay.2017.01.008

KHARRAZI, S. M.; MIRGHAFFARI, N.; DASTGERDI M. M.; SOLEIMANI, M. A novel post-modification of powdered activated carbon prepared from lignocellulosic waste through thermal tension treatment to enhance the porosity and heavy metals adsorption. Powder Technology, v. 366, p. 358368, 2020. http://doi.org/10.1016/j.powtec.2020.01.065

LARAZATOU, C.; PANAGIOTARAS, D.; PANAGOPOULOS, G.; POSPIŠIL, M.; PAPOULIS, D. Ca treated Palygorskite and Halloysite clay minerals for Ferrous Iron $\left(\mathrm{Fe}^{+2}\right.$ ) removal from water systems. Environmental Technology \& Innovation, v. 19, p. 10096, 2020. http://doi.org/10.1016/j.eti.2020.100961

LIU, J. REN, S.; CAO, J.; TSANG, D. C. W.; BEIYUAN, J.; PENG, Y.; WANG, J. Highly efficient removal of thallium in wastewater by $\mathrm{MnFe}_{2} \mathrm{O}_{4}$-biochar composite. Journal of Hazardous Materials, v. 401, p. 123311, 2021. http://doi.org/10.1016/j. jhazmat.2020.123311

LIU, Y.; YAN, C.; ZHANG, Z:; WANG, H.; ZHOU, S:; ZHOU, W. A comparative study on fly ash, geopolymer and faujasite block for $\mathrm{Pb}$ removal from aqueous solution. Fuel, v. 185, p. 181-189, 2016. https://doi.org/10.1016/j.fuel.2016.07.116

LOSEKANN, L.; TAVARES, F. Politica energética no brics: desafios da transição energética. Rio de Janeiro: IPEA/CEPAL, 2019.

LUUKKONEN, T.; RUNTTI, H.; NISKANEN, M.; TOLONEN, E.T.; SARKKINEN, M.; KEMPPAINEN, K.; LASSI, U. Simultaneous removal of Ni(II), As(III), and $\mathrm{Sb}(\mathrm{III})$ from spiked mine effluent with metakaolin and blast-furnace-slag geopolymers. Journal of environmental management, v. 166, p. 579-588, 2016. https://doi.org/10.1016/j.jenvman.2015.11.007

MALEKI, A.; HAJIZADEH, Z.; SHARIFI, V.; EMDADI, Z. A green, porous and eco-friendly magnetic geopolymer adsorbent for heavy metals removal from aqueous solutions. Journal of Cleaner Production, v. 215, p. 1233-1245, 2019. https://doi.org/10.1016/j.jclepro.2019.01.084

MALEKI, A.; MOHAMMAD, M.; EMDADI, Z.; ASIM, N.; AZIZI, M.; SAFAEI, J. Adsorbent materials based on a geopolymer paste for dye removal from aqueous solutions. Arabian Journal of Chemistry, v. 13, n. 1, p. 3017-3025, 2020. https://doi.org/10.1016/j.arabjc.2018.08.011 
MANE, V. S.; DEO MALL, I.; CHANDRA, S. V. Kinetic and equilibrium isotherm studies for the adsorptive removal of Brilliant Green dye from aqueous solution by rice husk ash. Journal of Environmental Management, v. 84, n. 4, p. 390-400, 2006. https://doi.org/10.1016/j.jenvman.2006.06.024

NGUEAGNI, P.; WOUMFO, E. D.; KUMAR, P. S.; SIÉWÉ, M.; VIEILLARD, J.; BRUN, N.; NKUIGUE, P. F. Adsorption of Cu(II) ions by modified horn core: effect of temperature on adsorbent preparation and extended application in river water. Journal of molecular liquids, v. 298, p. 112023, 2020. http://doi. org/10.1016/j.molliq.2019.112023

NOVAIS, R. M.; BURUBERRI, L. H.; SEABRA, M. P.; LABRINCHA, J. A. Novel porous fly-ash containing geopolymer monoliths for lead adsorption from wastewaters. Journal of Hazardous Materials, v. 318, p. 631-640, 2016. https:// doi.org/10.1016/j.jhazmat.2016.07.059

NOVAIS, R. M:; CARVALHEIRAS, J:; TOBALDI, D. M:; SEABRA, M. P:; PULLAR, R. C; LABRINCHA, J. A. Synthesis of porous biomass fly-ash based geopolymer spheres for efficient removal of methylene blue from wastewaters. Journal of Cleaner Production, v. 207, p. 350-362, 2019. https://doi.org/10.1016/j.jclepro.2018.09.265

NÚÑEZZ-GOMEZ, D:; RODRIGUES C:; LAPOLLI, F; LOBO-RECIO, M. A. Adsorption of heavy metals from coal acid mine drainage by shrimp shell waste: isotherm and continuous-flow studies. Journal of Environmental Chemical Engineering, v. 7, n. 1, p. 102787, 2019. http://doi.org/10.1016/j.jece.2018.11.032

RASAKI, S. A; BINGXUE, Z:; GUARECUCO, R.; THOMAS, T.; MINGHUI, Y. Geopolymer for use in heavy metals adsorption, and advanced oxidative processes: a critical review. Journal of Cleaner Production, v. 213, p. 42-58, 2019. https://doi.org/10.1016/j.jclepro.2018.12.145

ROSSI, C.; HAMMES, T.; VIER, R.; CARVALHO SANTOS, L.; REINHEIMER, R. Resíduos cerâmicos incorporados na composição de concretos e argamassas com o material pozolânico. Revista Gestão e Desenvolvimento em Contexto, v. 5, n. 1, p. 53-56, 2017.

RUNTTI, H.; TUOMIKOSKI, S.; KANGAS, T.; LASSI, U.; KUOKKANEN, T.; RÄMÖ, J. Chemically activated carbon residue from biomass gasification as a sorbent for iron(II), copper(II) and nickel(II) ions. Journal of Water Process Engineering, v. 4, p. 12-24, 2014. https://doi.org/10.1016/j.jwpe.2014.08.009

RYU, S.; NAIDU, G.; MOON, H.; VIGNESWARAN, S. Selective copper recovery by membrane distillation and adsorption system from synthetic acid mine drainage. Chemosphere, v. 260, p. 127528, 2020. https://doi.org/10.1016/j. chemosphere.2020.127528

SAHOO, H.; SENAPATI, D.; THAKUR, I. S.; NAIK, U. C. Integrated bacteria-algal bioreactor for removal of toxic metals in acid mine drainage from iron ore mines. Bioresource Technology Reports, v. 11, p. 100422, 2020. http://doi. org/10.1016/j.biteb.2020.100422

SANDHU, R.; SIDDIQUE, R. Influence of rice husk ash (RHA) on the properties of self-compacting concrete: a review. Construction and Building Materials, v.153, p. 751-764, 2017. http://doi.org/10.1016/j.conbuildmat.2017.07.165

SILVEIRA, A. N.; SILVA, R.; RUBIO, J. Treatment of acid mine drainage in south Brazil: comparative active processes and water reuse. International Journal of Mineral Processing, v. 93, n. 2, p. 103-109, 2009. https://doi.org/10.1016/j. minpro.2009.06.005
SIMATE, G.; NDLOVU, S. Acid mine drainage: challenges and opportunities Journal of Environmental Chemical Engineering, v. 2, n. 3, p. 1785-1803, 2014 https://doi.org/10.1016/j.jece.2014.07.021

SINGHAL, A.; GANGWAR, B. P.; GAYATHRY, J. M. CTAB modified large surface area nanoporous geopolymer with high adsorption capacity for copper ion removal. Applied Clay Science, v. 150, p. 106-114, 2017. http://doi.org/10.1016/j. clay.2017.09.013

SIYAL, A. A.; AZIZLI, K. A.; MAN, Z.; ISMAIL, L.; KHAN, M. I. Geopolymerization kinetics of fly ash based geopolymers using JMAK model. Ceramics International, v. 42, n. 14, p. 15575-15584, 2016. http://doi.org/10.1016/j. ceramint.2016.07.006

SOLIMAN, N. K.; MOUSTAFA, A. F. Industrial solid waste for heavy metals adsorption features and challenges: a review. Journal of Materials Research and Technology, v. 9, n. 5, p. 10235-10253, 2020. https://doi.org/10.1016/j. jmrt.2020.07.045

SUN, Z.; CUI, H.; AN, H.; TAO, D.; XU, Y.; ZHAI, J.; LI, Q. Synthesis and thermal behavior of geopolymer-type material from waste ceramic. Construction and Building Materials, v. 49, p. 281-287, 2013. https://doi.org/10.1016/j. conbuildmat.2013.08.063

UBALDO, M; SOUZA, V. Controle e mitigação dos impactos da drenagem ácida em operações de mineração. In: SOARES, Paulo Sergio Moreira; DOS SANTOS, Maria Dionísia Costa; POSSA, Mario Valente. Carvão brasileiro: tecnologia e meio ambiente. Rio de Janeiro: CETEM/MCT, p. 129-151, 2008.

VITAL, B.; BARTACEK, J.; ORTEGA-BRAVO, J. C.; JEISON, D. Treatment of acid mine drainage by forward osmosis: heavy metal rejection and reverse flux of draw solution constituents. Chemical Engineering Journal, v. 332, p. 85-91, 2018. https://doi.org/10.1016/j.cej.2017.09.034

WEILER, J.; AMARAL, J. R.; SCHNEIDER, I. A. H. Processamento de rejeito de carvão visando a redução de custos no tratamento da drenagem ácida de minas: estudo de caso na região carbonífera de Santa Catarina. Engenharia Sanitária e Ambiental, v. 21, n. 2, p. 337-345, 2016. https://doi.org/10.1590/ S1413-41522016116411

WORCH, E. Adsorption technology in water treatment: fundamentals, processes, and modeling. Berlin/Boston: Walter de Gruyter, 2012. 344 p.

WU, C. H.; LIN, C. F.; CHEN, W. R. Regeneration and reuse of water treatment plant sludge: adsorbent for cations. Journal of Environmental Science and Health. Part A, Toxic/Hazardous, Substances \& Environmental Engineering, v. 39, n. 3, p. 717-728, 2004. https://doi.org/10.1081/ese-120027737

YAN, S.; HE, P.; JIA, D.; WANG, Q.; LIU, J.; YANG, J.; HUANG, Y. A green and low-cost hollow gangue microsphere/geopolymer adsorbent for the effective removal of heavy metals from wastewaters. Journal of Environmental Management, v. 246, p. 174-183, 2019. http://doi.org/10.1016/j. jenvman.2019.05.120

YOUNGER, P. L.; JAYAWEERA, A.; ELLIOT, A.; WOOD, R.; AMOS, P. DAUGHERTY, A. J.; JOHNSON, D. B. Passive treatment of acidic mine waters in subsurface-flow systems: exploring raps and permeable reactive barriers. Land Contamination and Reclamation, v. 11, n. 2, p. 127-135, 2003 http://doi.org/10.2462/09670513.806 